\title{
Visit Adherence of Mild to Moderate Psoriasis Patients: A Mobile-Based Randomized Study
}

This article was published in the following Dove Press journal:

Patient Preference and Adherence

\begin{abstract}
Yi Zhao,' Gang Wang, (D) ${ }^{2}$ Wenqiong Ni, ${ }^{3}$ Zhiqiang Song, ${ }^{4}$ Kun Chen, ${ }^{5}$ Chunlei Zhang, (D) ${ }^{6}$ Shoumin Zhang, ${ }^{7}$ Yangfeng Ding, ${ }^{8}$ Min Zheng, ${ }^{9}$ Yulin Shi, ${ }^{10}$ Zhimiao Lin, (ID) ${ }^{11}$ Xiaomin Liu, ${ }^{12}$ Xiaofei Zhang, ${ }^{13}$ Qintian Zhou, ${ }^{14}$ Kazi Deluwar Ahmed ${ }^{14}$

'Department of Dermatology, Beijing Tsinghua Changgung Hospital, School of Clinical Medicine, Tsinghua University, Beijing, People's Republic of China; ${ }^{2}$ Department of Dermatology, Xijing Hospital, Fourth Military Medical University, Xi'an, People's Republic of China; ${ }^{3}$ Department of Dermatology, Zhengzhou Central Hospital Affiliated to Zhengzhou University, Zhengzhou, People's Republic of China; ${ }^{4}$ Department of Dermatology, Southwest Hospital, The Third Military Medical University, Chongqing, People's Republic of China; ${ }^{5}$ Institute of Dermatology, Chinese Academy of Medical Science and Peking Union Medical College, Nanjing, People's Republic of China; ${ }^{6}$ Department of Dermatology, Peking University Third Hospital, Beijing, People's Republic of China; ${ }^{7}$ Department of Dermatology, Henan Provincial People's Hospital, Zhengzhou 450003 People's Republic of China; ${ }^{8}$ Department of Dermatology, Shanghai Skin Disease Hospital, Shanghai, People's Republic of China; 'Department of Dermatology, Second Affiliated Hospital, Zhejiang University School of Medicine, Hangzhou, People's Republic of China; ${ }^{10}$ Department of Dermatology, Shanghai Tenth People's Hospital, Tongii University School of Medicine; Institute of Psoriasis, Tongji University School of Medicine, Shanghai, People's Republic of China; "'Department of Dermatology and Venereology, Peking University First Hospital, Beijing, People's Republic of China; ${ }^{2}$ Department of Dermatology, The University of Hong KongShenzhen Hospital, Shenzhen, People's Republic of China; ${ }^{13}$ Department of Clinical Epidemiology and Biostatistics, Beijing Tsinghua Changgung Hospital, School of Clinical Medicine, Tsinghua University, Beijing, People's Republic of China; ${ }^{14}$ Scientific Affairs and MSL Department, LEOPharma China, Shanghai, People's Republic of China
\end{abstract}

Correspondence: Yi Zhao

Department of Dermatology, Beijing Tsinghua Changgung Hospital, School of Clinical Medicine, Tsinghua University, No. 168 Litang Road, Beijing 102218, People's Republic of China

Email zhaoyimd@tsinghua.edu.cn

Gang Wang

Department of Dermatology, Xijing Hospital, Fourth Military Medical University, Xi'an 710032, People's Republic of China

Email xjwgang@fmmu.edu.cn
Objective: We aimed to prospectively evaluate the visit adherence in mild to moderate psoriasis patients.

Methods: Plaque psoriasis patients aged 18 or above who were prescribed with a twocomponent formula ointment were eligible for the study. The patients were randomly assigned to group $\mathrm{A}$ or $\mathrm{B}$, and received management with or without planned patientdoctor communication via a mobile platform. The outpatient visit was scheduled at week $2,8,16,28,48$, and 52. Visit adherence was evaluated as the visit rate of the patients.

Results: Two hundred twenty-one patients were included. Generally, the visit adherence dropped over time during follow-up. The visit rates in group A were 5.2-15.7\% through the 52 weeks, and similar rates were found in group B (7.5-17.0\%, vs group A, $P>0.05)$. A negative binomial regression model showed that older age and higher BSA were correlated with more frequent visits.

Conclusion: The visit adherence of mild to moderate psoriasis patients was very low in China. Proactive inquiries of the doctors via the mobile platform failed to improve the visit adherence of the patients.

Keywords: psoriasis, visit adherence, topical treatment

\section{Introduction}

Visit adherence, referring to the attendance at scheduled visits, is a concept that is gaining attention across medical fields but has been most extensively studied in patients with HIV. ${ }^{1}$ Studies have shown that visit adherence is essential for chronic disease management, not only improving treatment effect but also predicting the outcome of the patients. ${ }^{1,2}$ For chronic skin diseases such as psoriasis, long-term control is highly dependent on patient adherence. ${ }^{3,4}$ Studies have shown that improving adherence can lead to better treatment efficacy for the patients., ${ }^{4,5}$

Visit adherence in psoriasis patients is potentially important because most of the patients, especially those of mild to moderate disease, are managed in the outpatient department of dermatology. According to guidelines for psoriasis, efficacy and safety need to be evaluated continuously, or at least regularly at reasonable interval, and the clinical decision should be adjusted accordingly. This strategy is important for maintaining a minimal disease activity status, avoiding relapse, and improving the quality of life for the patients. ${ }^{6,7}$ Strategic scheduling of office visits can be crucial to enhance drug adherence. ${ }^{8}$ Therefore, visit adherence for psoriasis patients is necessary to be studied to support the real-world clinical decision.

Visit adherence in dermatology has not been studied vigorously. In China, due to the relatively short history of using the electronic medical recording system and 
the great diversity of hospital information systems, it is difficult to obtain robust data in retrospective studies. For this reason, we conducted a prospective mobile-based study to evaluate the visit adherence in mild to moderate psoriasis patients.

\section{Methods}

\section{Study Patients}

Mild to moderate $(\mathrm{BSA} \leq 10)$ plaque psoriasis patients aged 18 or above were eligible for the study if they were prescribed with a two-component formula ointment, calcipotriol and betamethasone dipropionate (Daivobet ${ }^{\circledR}$, LEO Pharma). The patients must be willing and able to communicate with the doctor through software on a smartphone platform. The patients included in the study should agree to the visit-plan with informed consent obtained beforehand.

The patients would be excluded if they were diagnosed as guttate, pustular or erythrodermic psoriasis, psoriatic arthritis, or skin infection; or had received biologics in the past three months, other systemic drugs or PUVA in the past four weeks, UVB treatment or other topical treatment for psoriasis in the past two weeks. Other exclusion criteria included allergy to the components of Daivobet ${ }^{\circledR}$, hypercalcemia, liver or kidney dysfunction, severe heart or mental disorders, alcohol or drug addiction, and Cushing's or Addison's disease. Pregnant or lactating women or those who intended to get pregnant during the study period; would also be excluded.

\section{Study Design}

\section{Randomization and Allocation}

This was a multi-center long-term study conducted in twelve hospitals between May 2017 and January 2019.
The randomization was performed according to a computer-generated random sequence. Patients included would be randomly assigned to group A or B. In group A, the patients would receive regular management plus the planned communication between the patients and the doctors on the mobile software platform. In group B, the patients would receive the same management without scheduled patient-doctor communication.

\section{Intervention}

All patients prescribed with Daivobet ${ }^{\circledR}$ were advised to follow a sequential treatment protocol. ${ }^{9}$ In the induction stage, use Daivobet ${ }^{\circledR}$ once daily for 2-4 weeks till the skin lesions become flat. In the transition stage, use Daivobet once every other day till the lesion color fades. Lastly, in the maintenance stage, use Daivobet ${ }^{\circledR}$ twice a week or Devonex ${ }^{\circledR}$ (LEO Pharma A/S, Ballerup, Denmark) once daily for at least eight weeks, then switch to 'treat-as-needed' till week 52 .

Doctors participated in this study were all certified dermatologists. A commercially available mobile application, namely Xingshulin (Xingshulin Information Technology (Beijing) Co. LTD), would be installed by each doctor and patient before participating in the study. The interface of the app is in Chinese. All patients would receive medical information automatically delivered via the application (Figure 1). The information included frequently asked-for information, reminder for application of the drug, reminder for regular visits, and self-assessment forms. If the patient asked a question via the platform, the doctor should respond to the patient in 24 hours. In group A, the mobile system would automatically send messages to the responsible doctors reminding them to initiate additional proactive

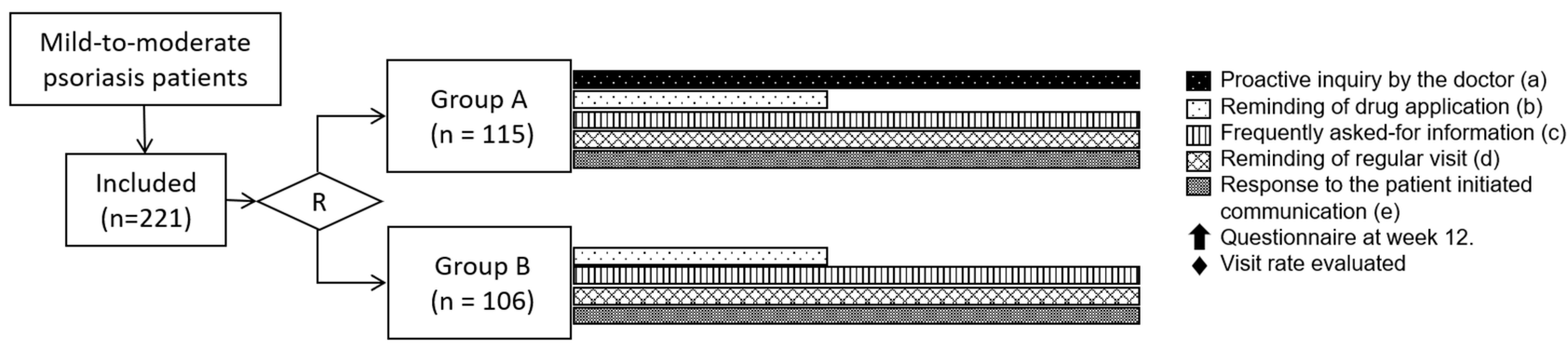

Follow-up planned

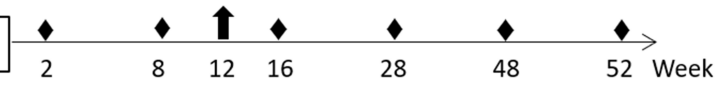

Figure I Study flow chart. "R" indicates randomization; (a) In group A, the mobile system would automatically send massages to the responsible doctor reminding them to initiate additional proactive communication with the patients twice in the first 4 weeks, and once in 4 weeks after the second month. Patients in group B would not receive such proactive communication; (b) once a week in the first 4 weeks, and once in two weeks after the second month till week 16; (c) twice a week in the first 4 weeks, then once a week till week 52; (d) visit planned at week 2, 8, 16, 28, 48 and 52, notification would be sent 48 hours before the visit; (e) If the patients initiated a communication via the platform, the responsible doctor should respond to the patient in 24 hours. 
communication with the patients twice in the first four weeks and once in four weeks after the second month. Patients in group B would not receive such proactive communication, but they were allowed to initiate communication with the doctors if needed. (Study flow chart shown in Figure 1). The patients were not informed that their visit adherence would be monitored.

\section{Data Collection and Adherence Evaluation}

Clinical data collected include the patients' sex, age, education status, and complications, as well as the type, onset time, and treatment of psoriasis. The outpatient visit was planned at week 2, 8, 16, 28, 48, and 52. Visit adherence was evaluated as the patients' visit rate at week 2, 8, 16, 28, 48, and 52 .

A questionnaire was sent to the patients at week 12 to evaluate the adherence of drug application in the past four weeks. The questions included in the questionnaire were: 1. How frequently did you use the drug? 2. How often did you fail to use the drug because of forgetfulness? 3. How often did you fail to use the drug because you thought it was unnecessary? 4. How often did you fail to use the drug because of the burden caused by drug application? 5. The average time ( $\mathrm{min}$ ) needed to apply the drug each day? For question 1-4, a 5-score response scale was defined as 0 . Never, 1. Rarely, 2. Sometimes, 3. Often, and 4. Always. For question 5 , the 5 -score response scale was: 0 . $0 \mathrm{~min}, 1$. 1-5min, 2. 6-10min, 3. 11-15min, and 4. $\geq 16 \mathrm{~min}$.

\section{Statistical Analyses}

The differences of demographic and clinical variables between group A and B were analyzed using one-way ANOVA and Kruskal Wallis tests for continuous variables and Chi-Square or Fisher's exact tests for categorical variables. Then, a negative binomial regression model was used to explore the baseline variables in association with the visit adherence, adjusted for sociodemographic variables which were significant in bivariate analysis. STATA version 15.0 (StataCorp, College Station, TX, USA) was used for all analyses. $P<0.05$ was considered statistically significant.

\section{Results}

\section{Demographic Profile}

Two hundred twenty-one patients were included in the study. $115(52.0 \%)$ and $106(48.0 \%)$ of them were in group A and B, respectively. The mean age of the patients was $34.1 \pm 10.6$. $105(47.5 \%)$ of them were younger than $30,62(28.1 \%)$ were aged 30-40, and 54 (24.4\%) were older than 40. 216 (97.7\%) patients were Han ethnicity, $109(49.3 \%)$ received college education or above, and 19 $(8.6 \%)$ had an allergy history. $86(38.9 \%)$ of the patients had a history of psoriasis for 0-5 years, and 198 (89.6\%) had no co-morbidities. 93 (42.1\%) patients never received treatment for psoriasis, and 204 (92.3\%) had received medication for indications other than psoriasis. 183 $(82.8 \%)$ of the patients were scored $\mathrm{PGA} \leq 2$, and 135 $(61.1 \%) \mathrm{BSA} \leq 6$. In group $\mathrm{A}$, there were an average of $6.7 \pm 5.3$ proactive inquires between the patients and the responsible doctors. In comparison, only $1.4 \pm 0.5$ communication took place with only 13 patients in group B (Table 1).

\section{Visit Rate of the Patients}

The visit rates in group A were $13.9 \%, 11.3 \%, 15.7 \%$, $15.7 \%, 5.2 \%$ and $9.6 \%$ at week $2,8,16,28,48$ and 52 , respectively. In group $\mathrm{B}$, the visit rates were $12.3 \%$, $17.0 \%, 14.2 \%, 11.3 \%, 8.5 \%$ and $7.5 \%$ at week $2,8,16$, 28, 48 and 52, respectively. No statistical significance was detected for the visit rates between the two groups $\left(c^{2}=4.740, P>0.05\right)$. Table 2 and Figure 2 demonstrate the visit profile of both groups.

\section{Factors Correlated to Total Visits}

In the negative binomial regression model used to analyze the factors in association with the total number of visits, older age (except for age over 60) and higher BSA was found to be associated with more visits (Table 3 ).

\section{Adherence to Drug Application}

Forty-one patients responded to the questionnaire at week 12. During the past four weeks, $13(31.7 \%)$ of the patients responded "never" to "sometimes" used the drug (Table 4).

\section{Discussion}

Psoriasis is a common chronic relapsing inflammatory disease which affects $0.47 \%$ of the population in China and $2-3 \%$ worldwide, imposing a significant impact on patients' quality of life. ${ }^{10}$ Topical treatment is the mainstay of treatment for mild to moderate psoriasis. ${ }^{11}$ Sequential treatment of a long period of up to 52 weeks has been shown to lead to better control and minimize the number of relapses for psoriasis patients. ${ }^{9,11-13}$ However, for such long-term management strategies, adherence of the patients is essential for achieving proper response. In our study, we prospectively studied the visit adherence of the mild to moderate psoriasis patients. According to the 
Table I Demographic Characteristics of the Patients

\begin{tabular}{|c|c|c|c|}
\hline & Group A & Group B & Total \\
\hline N\% & $115(52.0)$ & $106(48.0)$ & 221 \\
\hline \multicolumn{4}{|l|}{ Sex } \\
\hline Male & $58(50.4)$ & 63(59.4) & $|2|(54.8)$ \\
\hline Female & $57(49.6)$ & $43(40.6)$ & $100(45.2)$ \\
\hline \multicolumn{4}{|l|}{ Age } \\
\hline$<30$ & $58(50.4)$ & $47(44.3)$ & $105(47.5)$ \\
\hline $30 \sim 40$ & $32(27.8)$ & $30(28.3)$ & $62(28.1)$ \\
\hline $40 \sim 50$ & $17(14.8)$ & $24(22.6)$ & $4 \mid(\mid 8.6)$ \\
\hline $50 \sim 60$ & $6(5.2)$ & $2(1.9)$ & $8(3.6)$ \\
\hline$>60$ & $2(1.7)$ & $3(2.8)$ & $5(2.3)$ \\
\hline \multicolumn{4}{|l|}{ Nationality } \\
\hline Han & III(96.5) & 105(99.1) & $216(97.7)$ \\
\hline Non-Han & $4(3.5)$ & $\mathrm{I}(0.9)$ & $5(2.3)$ \\
\hline \multicolumn{4}{|l|}{ Education } \\
\hline Middle school or below & $25(21.7)$ & $18(17.0)$ & $43(19.5)$ \\
\hline High school & $36(31.3)$ & $33(31.1)$ & $69(31.2)$ \\
\hline College & $48(4 \mid .7)$ & $52(49.0)$ & $100(45.2)$ \\
\hline Master or above & $6(5.2)$ & $3(2.8)$ & $9(4.1)$ \\
\hline Allergic history & $9(7.8)$ & $10(9.4)$ & $19(8.6)$ \\
\hline \multicolumn{4}{|l|}{ Duration of psoriasis (Year)* } \\
\hline $0 \sim 5$ & $54(47)$ & $32(30.2)$ & $86(38.9)$ \\
\hline $5 \sim 10$ & $18(15.7)$ & $30(28.3)$ & $48(21.7)$ \\
\hline $10 \sim 15$ & $27(23.5)$ & $19(17.9)$ & $46(20.8)$ \\
\hline $15 \sim 20$ & $8(7)$ & $8(7.5)$ & $16(7.2)$ \\
\hline$>20$ & $8(7)$ & $17(16)$ & $25(\mid 1.3)$ \\
\hline \multicolumn{4}{|l|}{ Complications } \\
\hline Metabolic Syndrome & $8(7.0)$ & $15(14.2)$ & $23(10.4)$ \\
\hline Non-MS & 107(93.0) & $91(85.8)$ & 198(89.6) \\
\hline \multicolumn{4}{|l|}{ PGA* } \\
\hline$\leq 1$ & $46(40.0)$ & $30(28.3)$ & $76(34.4)$ \\
\hline 2 & $56(48.7)$ & $5 I(48.1)$ & $107(48.4)$ \\
\hline $3 \sim 5$ & $13(\mid 1.3)$ & $25(23.6)$ & $38(17.2)$ \\
\hline \multicolumn{4}{|l|}{ BSA } \\
\hline$\leq 3$ & $52(45.2)$ & $35(33)$ & $87(39.4)$ \\
\hline $4 \sim 6$ & $22(19.1)$ & $26(24.5)$ & $48(21.7)$ \\
\hline $7 \sim 10$ & $4 I(35.7)$ & $45(42.5)$ & $86(38.9)$ \\
\hline Previous psoriasis medication & $61(53.0)$ & $67(63.2)$ & $128(57.9)$ \\
\hline No & $54(47.0)$ & $39(36.8)$ & $93(42.1)$ \\
\hline \multicolumn{4}{|l|}{ Prescribed treatment } \\
\hline Topical & $89(77.4)$ & $82(77.4)$ & $|7|(77.4)$ \\
\hline Topical + UV & $1 \mathrm{I}(9.6)$ & $15(\mid 4.2)$ & $26(11.8)$ \\
\hline Sys \pm Topical & $15(13.0)$ & $8(7.5)$ & $23(10.4)$ \\
\hline Systemic & $0(0.0)$ & $I(0.9)$ & $I(0.5)$ \\
\hline \multicolumn{4}{|l|}{ Topical treatment } \\
\hline Daivobet only & $84(73.0)$ & $67(63.2)$ & $151(68.3)$ \\
\hline
\end{tabular}

(Continued)
Table I (Continued).

\begin{tabular}{|l|l|l|l|}
\hline & Group A & Group B & Total \\
\hline Daibobet + other topics & $28(24.3)$ & $37(34.9)$ & $65(29.4)$ \\
Other topics & $3(2.6)$ & $\mathrm{I}(0.9)$ & $4(1.8)$ \\
Non & $0(0.0)$ & $1(0.9)$ & $1(0.5)$ \\
\hline $\begin{array}{l}\text { Systemic treatment prescribed } \\
\text { Retinoids }\end{array}$ & $0(0.0)$ & $2(0.9)$ & $2(0.9)$ \\
Other systemic drugs & $15(13.0)$ & $7(6.6)$ & $22(10.0)$ \\
Non & $100(87.0)$ & $97(91.5)$ & $197(89.1)$ \\
\hline
\end{tabular}

Note: $* \mathrm{P}<0.05$.

guidelines and clinical practice, we hypothesized that planned follow-up at week 2, 8, 16, 28, 48, 52 in a year was reasonable. And the patients all agreed to the followup plan at baseline.

\section{Visit Adherence}

In this study, we found the visit adherence in psoriasis patients was very low. The visit rate quickly dropped to $13.1 \%$ two weeks after baseline and continued falling slowly during the whole course. Our study was performed with the aid of a mobile system, which automatically delivered notice and information to the patients. Such tools have been reported to be able to increase the adherence and treatment effect for psoriasis. ${ }^{14,15}$ Therefore, the visit adherence in dermatology without proper management system might be worse.

\section{Factors Affecting Visit Adherence}

In this study, the doctor's inquiry initiation was not mandatory. In group A, an average of $6.7 \pm 5.3$ proactive inquiries were given to the patients by the responsible doctors. However, the doctors' proactive communication failed to increase visit adherence.

Table 2 Visit Rates in Each Group

\begin{tabular}{|l|l|l|l|}
\hline Visit & Group A n (\%) & Group B n (\%) & Total \\
\hline Week 0 & II5(I00.0) & $106(100.0)$ & $221(100.0)$ \\
Week 2 & $16(13.9)$ & $13(12.3)$ & $29(13.1)$ \\
Week 8 & $13(11.3)$ & $18(17.0)$ & $31(14.0)$ \\
Week 16 & $18(15.7)$ & $15(14.2)$ & $33(14.9)$ \\
Week 28 & $18(15.7)$ & $12(11.3)$ & $30(13.6)$ \\
Week 48 & $6(5.2)$ & $9(8.5)$ & $15(6.8)$ \\
Week 52 & II(9.6) & $8(7.5)$ & $19(8.6)$ \\
\hline
\end{tabular}

Note: $C^{2}=4.740, P>0.05$. 
Visit and lost-of-visit through the 52 weeks

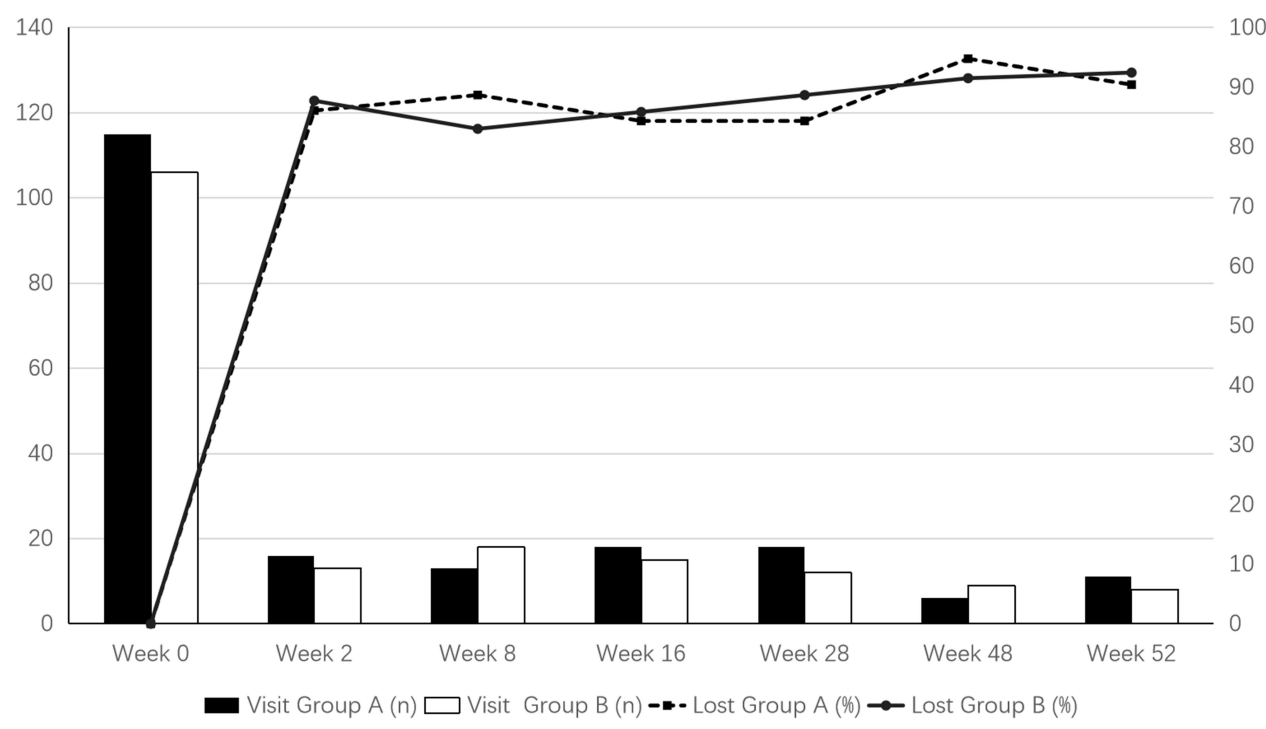

Figure 2 Visit and lost-of-visit of the patients. Number of patients remained visit or lost to visit through the 52 weeks. Filled bar: visit in group A, empty bar: visit in group B, full line: lost-of-visit in group A, dotted line: lost-of-visit in group B.

We were able to address some of the reasons why the patients continued visiting the doctors. In our regression analysis, older age (except for age over 60), and higher baseline BSA were correlated with a higher visit adherence. People aged 30-60 might be more concerned about their disease condition than those younger or retired. The disease severity entailing management might increase such kind of concern. Thus, the two factors might promote the patient to revisit.

We could not track the personal reason for the patients lost to follow-up. In China, prior appointment before outpatient visits has not become a routine practice. Many of our patients were not scheduled manually by the medical

Table 3 Negative Binomial Regression for Patient Visit

\begin{tabular}{|l|l|l|l|l|l|}
\hline & IRR & $\begin{array}{l}\text { Std. } \\
\text { Err. }\end{array}$ & $\begin{array}{l}\text { 95\% Conf. } \\
\text { Interval }\end{array}$ & $\mathbf{z}$ & $\boldsymbol{P}$ \\
\hline $\begin{array}{l}\text { Group } \\
\text { Female }\end{array}$ & 1.01 & 0.11 & $0.82-1.24$ & 0.09 & 0.93 \\
1.14 & 0.12 & $0.93-1.4$ & 1.27 & 0.21 \\
\hline Age & & & & & \\
$30 \sim 40$ & 1.29 & 0.16 & $1.01-1.65$ & 2.07 & 0.04 \\
$40 \sim 50$ & 1.32 & 0.18 & $1-1.73$ & 1.96 & 0.05 \\
$50 \sim 60$ & 1.79 & 0.44 & $1.11-2.89$ & 2.39 & 0.02 \\
$>60$ & 0.99 & 0.38 & $0.46-2.11$ & -0.04 & 0.97 \\
\hline BSA & & & & & \\
$4 \sim 6$ & 1.06 & 0.15 & $0.79-1.41$ & 0.37 & 0.71 \\
$7 \sim 10$ & 1.27 & 0.15 & $1.01-1.6$ & 2.02 & 0.04 \\
cons & 1.22 & 0.16 & $0.94-1.59$ & 1.51 & 0.13 \\
\hline
\end{tabular}

Abbreviation: IRR, incidence rate ratio for patient visit. professionals for the next visit. This might have an impact on visit adherence of the patients. In most hospitals, dermatology patients could be registered on-site. In our study, all participating dermatologists were asked to guarantee the registration for the patients included. And the medical insurance coverage of Chinese citizens was $95 \% .{ }^{16}$ Therefore, the registration availability and cost for seeing the doctor might not be a significant barrier to visit the dermatologists.

\section{Adherence to Drug Application}

The patients who responded to the survey at week 12 might have better adherence than those who failed to respond. About

Table 4 Survey on Drug Application at Week 12

\begin{tabular}{|l|l|l|}
\hline Score* & $0-2$ & $3-4$ \\
\hline I. How frequent did you used the drug? & $13(31.7)$ & $28(68.3)$ \\
\hline $\begin{array}{l}\text { 2. How often did you fail to use the drug because } \\
\text { of forgotten? }\end{array}$ & $35(85.4)$ & $6(14.6)$ \\
\hline $\begin{array}{l}\text { 3. How often did you fail to use the drug because } \\
\text { you thought it was unnecessary for your disease } \\
\text { condition? }\end{array}$ & $35(85.4)$ & $6(14.6)$ \\
\hline $\begin{array}{l}\text { 4. How often did you fail to use the drug because } \\
\text { of the burden caused by drug application? }\end{array}$ & $38(92.7)$ & $3(7.3)$ \\
\hline $\begin{array}{l}\text { 5. The average time needed to apply the drug? } \\
\text { (min/d) }\end{array}$ & $26(63.4)$ & $15(36.6)$ \\
\hline
\end{tabular}

Notes: ${ }^{*} \mathrm{~N}=4 \mathrm{I}$. Regarding the past 4 weeks, for question $\mathrm{I}-4$, the 5 -score scale response was defined as: 0 . Never, I. Rare, 2. Sometimes, 3. Often and 4. Always. For question 5, the 5-score scale response was: 0 . $0 \mathrm{~min}, 1-1-5 \mathrm{~min}, 2$. 6-10 $\mathrm{min}, 3$. $\mathrm{II}-15 \mathrm{~min}$ and 4 . $\geq 16 \mathrm{~min}$. 
one-third of the 41 responding patients "never" to "sometime" used the drug during the past four weeks. Therefore, the overall adherence can be even more worrisome.

\section{Limitation}

For HIV-infected patients, studies have shown that increased adherence with regularly scheduled visits is not only associated with reduced viral loads but also improved survival. ${ }^{17,18}$ The treatment efficacy of the two-component product with proper compliance has been shown in other studies. ${ }^{19-21}$ Whether the reduced visit adherence would affect the effectiveness of the treatment also deserves further investigation. However, we could not objectively evaluate the treatment efficacy or safety during this study due to the loss of followup. We did not study the visit adherence of severe psoriasis patients. It is also interesting to study more detailed aspects in application of the smartphone platform (eg how often did the patient opened the app). However, due to the setting of the platform, such evaluation was not able to be conducted.

\section{Summary and Conclusion}

Patients were asked to follow a certain visiting plan as a norm in everyday practice. But this study shows that the patients would not follow the visiting plan actually even when alerted by smartphone platforms and additional inquiries from physicians. Therefore, management relying on such kind of plan would be insecure under current circumstances. The efficacy and safety would be hard to ensure, and the long-term risk, such as metabolic complications and psoriatic arthritis, would be challenging to manage. Strategies consist of more complicated interventions might be able to achieve a significant improvement of adherence. ${ }^{22}$ However, the application of such kind of interventions is highly dependent on real-world settings. Therefore, great needs still exist for evaluating the real-world effectiveness of such interventions.

In conclusion, the visit adherence of mild to moderate psoriasis patients was very low in China. Proactive inquiries of the doctors via the smartphone software platform failed to improve the visit adherence of the patients.

\section{Key Message}

Visit adherence of mild-to-moderate psoriasis patients was found to be very low regardless of proactive inquiries of the doctors in this mobile-based study.

\section{Data Sharing Statement}

The data that support the findings of this study are available on request from the corresponding author.

\section{Statement of Ethics}

The study was conducted ethically in accordance with the World Medical Association Declaration of Helsinki. The study was approved by the Ethics Committee of Beijing Tsinghua Changgung Hospital. All patients have given written informed consent at the beginning of the study.

\section{Author Contributions}

All authors made a significant contribution to the work reported, whether that is in the conception, study design, execution, acquisition of data, analysis and interpretation, or in all these areas; took part in drafting, revising or critically reviewing the article; gave final approval of the version to be published; have agreed on the journal to which the article has been submitted; and agree to be accountable for all aspects of the work.

\section{Funding}

This research is sponsored by LEO Pharma. The sponsor participated in study design and study conduction in cooperation with the investigators, while not involved in data collection, analyses or interpretation.

\section{Disclosure}

QZ and KDA are employees of LEO Pharma. The authors report no other conflicts of interest in this work.

\section{References}

1. Ramakrishnan MS, Yu Y, VanderBeek BL. Association of visit adherence and visual acuity in patients with neovascular age-related macular degeneration: secondary analysis of the comparison of age-related macular degeneration treatment trial. JAMA Ophthalmol. 2020;138 (3):237. doi:10.1001/jamaophthalmol.2019.4577

2. Park WB, Choe PG, Kim S-H, et al. One-year adherence to clinic visits after highly active antiretroviral therapy: a predictor of clinical progress in HIV patients. J Intern Med. 2007;261(3):268-275. doi:10.1111/j.1365-2796.2006.01762.x

3. Zaghloul SS, Goodfield MJD. Objective assessment of compliance with psoriasis treatment. Arch Dermatol. 2004;140(4):408-414. doi:10.1001/archderm.140.4.408

4. Carroll CL, Feldman SR, Camacho FT, et al. Better medication adherence results in greater improvement in severity of psoriasis. Br J Dermatol. 2004;151(4):895-897. doi:10.1111/j.1365-2133.2004.06174.x

5. Augustin M, Holland B, Dartsch D, et al. Adherence in the treatment of psoriasis: a systematic review. Dermatol Basel Switz. 2011;222 (4):363-374. doi:10.1159/000329026

6. Menter A, Korman NJ, Elmets CA, et al. Guidelines of care for the management of psoriasis and psoriatic arthritis. Section 3. Guidelines of care for the management and treatment of psoriasis with topical therapies. $J$ Am Acad Dermatol. 2009;60(4):643-659. doi:10.1016/j.jaad.2008.12.032

7. Menter A, Strober BE, Kaplan DH, et al. Joint AAD-NPF guidelines of care for the management and treatment of psoriasis with biologics. J Am Acad Dermatol. 2019;80(4):1029-1072. doi:10.1016/j.jaad.2018. 11.057 
8. Heaton E, Levender MM, Feldman SR. Timing of office visits can be a powerful tool to improve adherence in the treatment of dermatologic conditions. J Dermatol Treat. 2013;24(2):82-88. doi:10.3109/ 09546634.2011.588194

9. Koo J, Blum RR, Lebwohl M. A randomized, multicenter study of calcipotriene ointment and clobetasol propionate foam in the sequential treatment of localized plaque-type psoriasis: short- and long-term outcomes. J Am Acad Dermatol. 2006;55(4):637-641. doi:10.1016/j. jaad.2006.05.026

10. Ding X, Wang T, Shen Y, et al. Prevalence of psoriasis in China: a population-based study in six cities. Eur J Dermatol. 2012;22 (5):663-667. doi:10.1684/ejd.2012.1802

11. Kragballe K, Austad J, Barnes L, et al. Efficacy results of a 52-week, randomised, double-blind, safety study of a calcipotriol/betamethasone dipropionate two-compound product (Daivobet/Dovobet/ Taclonex) in the treatment of psoriasis vulgaris. Dermatol Basel Switz. 2006;213(4):319-326. doi:10.1159/000096069

12. Augustin M, Mrowietz U, Bonnekoh B, et al. Topical long-term therapy of psoriasis with vitamin $\mathrm{D}_{3}$ analogues, corticosteroids and their two compound formulations: position paper on evidence and use in daily practice. J Dtsch Dermatol Ges. 2014;12:667-682.

13. Lambert J, Hol CW, Vink J. Real-life effectiveness of once-daily calcipotriol and betamethasone dipropionate gel vs. ointment formulations in psoriasis vulgaris: final analysis of the 52-week PRO-long study. J Eur Acad Dermatol Venereol. 2015;29(12):2349-2355. doi:10.1111/jdv.13230

14. Balato N, Megna M, Di Costanzo L, et al. Educational and motivational support service: a pilot study for mobile-phone-based interventions in patients with psoriasis. Br J Dermatol. 2013;168(1):201-205. doi:10.1111/j.1365-2133.2012.11205.x

15. Svendsen MT, Andersen F, Andersen KH, et al. A smartphone application supporting patients with psoriasis improves adherence to topical treatment: a randomized controlled trial. Br J Dermatol. 2018;179 (5):1062-1071. doi:10.1111/bjd.16667
16. National Healthcare Security Administration. Development statistics bulletin of national basic medical insurance. 2018. Available from: http://www.nhsa.gov.cn. Accessed April 11, 2020.

17. Giordano TP, Gifford AL, White AC, et al. Retention in care: a challenge to survival with HIV infection. Clin Infect Dis. 2007;44 (11):1493-1499. doi:10.1086/516778

18. Mugavero MJ, Lin H, Willig JH, et al. Missed visits and mortality among patients establishing initial outpatient HIV treatment. Clin Infect Dis. 2009;48(2):248-256. doi:10.1086/595705

19. Guenther L, Van de Kerkhof PCM, Snellman E, et al. Efficacy and safety of a new combination of calcipotriol and betamethasone dipropionate (once or twice daily) compared to calcipotriol (twice daily) in the treatment of psoriasis vulgaris: a randomized, double-blind, vehicle-controlled clinical trial. $\mathrm{Br} \quad J$ Dermatol. 2002;147 (2):316-323. doi:10.1046/j.1365-2133.2002.04967.x

20. Kragballe K, Hoffmann V, Ortonne JP, et al. Efficacy and safety of calcipotriol plus betamethasone dipropionate scalp formulation compared with calcipotriol scalp solution in the treatment of scalp psoriasis: a randomized controlled trial. $\mathrm{Br}$ J Dermatol. 2009;161 (1):159-166. doi:10.1111/j.1365-2133.2009.09116.x

21. Ma L, Yang Q, Yang H, et al. Calcipotriol plus betamethasone dipropionate gel compared with calcipotriol scalp solution in the treatment of scalp psoriasis: a randomized, controlled trial investigating efficacy and safety in a Chinese population. Int J Dermatol. 2016;55(1):106-113. doi:10.1111/ijd.12788

22. Reich K, Zschocke I, Bachelez H, et al. A Topical Treatment Optimization Programme (TTOP) improves clinical outcome for calcipotriol/betamethasone gel in psoriasis: results of a 64-week multinational randomized Phase IV study in 1790 patients (PSO-TOP). Br J Dermatol. 2017;177(1):197-205. doi:10.1111/ bjd. 15466
Patient Preference and Adherence

\section{Publish your work in this journal}

Patient Preference and Adherence is an international, peer-reviewed, open access journal that focusing on the growing importance of patient preference and adherence throughout the therapeutic continuum. Patient satisfaction, acceptability, quality of life, compliance, persistence and their role in developing new therapeutic modalities and compounds to optimize clinical outcomes for existing disease

\section{Dovepress}

states are major areas of interest for the journal. This journal has been accepted for indexing on PubMed Central. The manuscript management system is completely online and includes a very quick and fair peer-review system, which is all easy to use. Visit http:// www.dovepress.com/testimonials.php to read real quotes from published authors. 